\title{
HAS3-related hyaluronan enhances biological activities necessary for metastasis of osteosarcoma cells
}

\author{
KATSUHIRO TOFUKU, MASAHIRO YOKOUCHI, TAKASHI MURAYAMA, \\ SHUSAKU MINAMI and SETSURO KOMIYA \\ Department of Orthopaedic Surgery, Kagoshima Graduate School of Medical and Dental Sciences, \\ 8-35-1 Sakuragaoka, Kagoshima 890-8520, Japan
}

Received February 10, 2006; Accepted April 7, 2006

\begin{abstract}
Several studies have suggested that increased production of hyaluronan (HA) is associated with metastatic behavior in various malignant tumors. To our knowledge, HA molecular weights required for metastasis are still unsolved in osteosarcoma. We examined the size of HA and hyaluronan synthase (HAS) isoforms related to biological functions required for metastasis in the LM8 stably highly metastatic osteosarcoma cell line. We found that HA of molecular weight which HAS3 produces enhanced biological functions related to metastasis such as cell proliferation, invasion, and degradation of extracellular matrix. Moreover, cell proliferation and invasion were inhibited by suppressing the activity of HAS3 expressed in LM8 cells, using hyaluronan synthase suppressor, 4-methylumbelliferone (MU). HA with the molecular weight related to HAS2 was the most adherent to CD44 in LM8 cells, suggesting that HAS2 may play an important role in pericellular coat formation. These results suggest that HAS3-related HA enhances crucial biological activities necessary for metastasis and that HAS2related HA offers an advantageous environment for osteosarcoma cells.
\end{abstract}

\section{Introduction}

The identification of effective neoadjuvant chemotherapy in combination with surgery for osteosarcoma patients has led to a significant improvement in patient outcome over the last several decades. However, there are still a certain number of non-responders who do not benefit from these improvements. Despite an increase in the long-term rate of disease-free survival, metastasis develops in $30-40 \%$ of patients, $90 \%$ of whom rarely respond to salvage treatment (1). It is therefore

Correspondence to: Dr Setsuro Komiya, Department of Orthopaedic Surgery, Kagoshima Graduate School of Medical and Dental Sciences, 8-35-1 Sakuragaoka, Kagoshima 890-8520, Japan

E-mail: skomiya@m3.kufm.kagoshima-u.ac.jp

Key words: hyaluronan, molecular weight, hyaluronan synthase, osteosarcoma, 4-methylumbelliferone believed that alternative strategies for the treatment of osteosarcoma patients are necessary.

Several studies have suggested that increased production of hyaluronan (HA) is associated with metastatic behavior in certain types of malignant tumors, including breast cancer (2-4), lung cancer (5), colon cancer (6), and mesotheliomas (7). The increased levels of HA in the serum of some cancer patients are significantly elevated over those of normal individuals $(6,8,9)$. Thus, there appears to be a correlation between HA production and metastatic behavior.

HA is a high-molecular-weight glycosaminoglycan composed of repeating units of GlcNAc- $\beta(1 \rightarrow 4)$-GlcUA- $\beta$ $(1 \rightarrow 3)$. This molecule is a major component of most extracellular matrices and plays critical roles in physiological functions such as embryogenesis, wound healing, and tumorigenesis (8). It also interacts with cell surface receptors such as CD44, RHAMM, and LYVE-1 (10-12), and regulates cell proliferation, migration, and differentiation (13). CD44 is a multifunctional adhesion receptor involved in cell-cell as well as in cell-matrix interaction, and plays important roles in invasion and metastasis. CD44 has many variant forms, which are generated by alternative splicing, and the increase in expression of certain variant CD44 isoforms appears to parallel the acquisition of invasive and metastatic potential in some malignancies $(14,15)$. In many malignancies, a correlation between overexpression of CD44 and poor prognosis has been reported $(16,17)$. An immunohistochemical study showed that overexpression of CD44 was correlated with poor prognosis in patients with osteosarcoma (18). HA-CD44 interaction may play a pivotal roll in invasion and metastasis by osteosarcoma.

Several studies have suggested that high-and low-molecularweight species of HA exhibit different biological effects on cells $(19,20)$. To our knowledge, how HA molecular weight is related to biological effects required for invasion and metastasis such as cell proliferation, motility, and degradation of extracellular matrix is still unclear for osteosarcoma.

HA is synthesized by a membrane-associated hyaluronan synthase (HAS) from the precursors UDP-glucuronic acid and UDP-N-acetylglucosamine (21). Three distinct mammalian HA synthases, HAS1, HAS2, and HAS3, have been identified and their properties examined (21-23). The three HAS isoforms are distinguished from each other with respect to the size of the HA produced by the different isoforms, with HAS3 
producing a smaller HA than either HAS1 or HAS2 (23). The existence of three different HAS isoforms implies that biological functions required for metastasis are regulated by control of the expressions and activities of the HAS isoforms, since HA plays various biological and physiological roles, some of which are size-dependent.

In this study, we examined the size of the HA and HAS isoforms involved in biological functions required for invasion and metastasis in the LM8 murine osteosarcoma cell line with high pulmonary metastatic potential (24). We found that HA of the molecular weight HAS3 produces promoted biological functions crucial for metastasis such as cell proliferation, invasion, and degradation of extracellular matrix. We suppressed activity of HAS3 in LM8 cells using the hyaluronan synthase suppressor, 4-methylumbelliferone (MU), and observed that both cell proliferation and invasion were inhibited. Based on this observation, we found that cell proliferation and invasion, biological functions crucial for metastasis, is promoted by the activity of HAS3. In addition, LM8 cells were most adherent to HA of the molecular size that HAS2 produces. This observation implied that cell adhesion to HA which HAS2 produces is related to HA-rich pericellular coat formation and HA-rich extracellular matrix, which plays an important role in providing a suitable environment for cell division, migration, and protection from cytolytic lymphocytes $(25,26)$.

\section{Materials and methods}

Reagents. HA was a generous gift from Seikagaku Corporation (Tokyo, Japan). Anti-FAK antibody (C-903), anti-phosphotyrosin antibody (PY99), anti-phospho Erk antibody (E-4), and anti-Erk2 antibody (D-2) were purchased from Santa Cruz Biotechnology, Inc. (CA, USA). 4-methylumbelliferone (MU) was purchased from Nacalai Tesque, Inc. (Kyoto, Japan). AntiCD44 mAb (KM81) was purchased from Cedarlane (Ontario, Canada).

Cell line and tumor samples. The LM8 mouse osteosarcoma cell line was cultured in Dulbecco's modified Eagle's medium (DMEM) supplemented with 10\% fetal bovine serum (FBS), penicillin, and streptomycin at $37^{\circ} \mathrm{C}$ in $5 \% \mathrm{CO}_{2}$. Tumor samples from osteosarcoma patients were collected with informed consent according to an Institutional Review Broad-approved protocol of Kagoshima University. Fourteen tumor samples obtained by biopsy with the histologic diagnosis of conventional osteosarcoma were fresh-frozen and stored at $-80^{\circ} \mathrm{C}$.

$R N A$ isolation and RT-PCR. Total RNA was extracted from LM8 cells with the High Pure RNA Isolation Kit (Roche Applied Science, Penzberg, Germany) and the tumor tissue was homogenized with TRIzol reagent according to the protocol of the manufacturer (Gibco-BRL, Grand Island, NY). RNA samples ( $1 \mu \mathrm{g})$ were reverse-transcribed by Random Primer and Rever Tra Ace reverse transcriptase (Toyobo Co., Osaka, Japan), and the cDNA was amplified using Takara Ex Taq ${ }^{\mathrm{TM}}$ DNA polymerase (Takara Bio Inc., Otus, Japan) with the Applied Biosystems Gene Amp PCR System 9700. The PCR products were resolved by $2 \%$ agarose gel electro- phoresis containing ethidium bromide. Amplifications of cDNA were performed for $3 \mathrm{~min}$ at $98^{\circ} \mathrm{C}$, followed by 30 cycles for $10 \mathrm{sec}$ at $98^{\circ} \mathrm{C}, 30 \mathrm{sec}$ at $57^{\circ} \mathrm{C}$, and $1 \mathrm{~min}$ at $72^{\circ} \mathrm{C}$, and strand completion was maximized by extending the final incubation at $72^{\circ} \mathrm{C}$ for an additional $7 \mathrm{~min}$. Sequences of the PCR primers are listed in Table I. Levels of G3PDH mRNA were monitored as internal controls.

Cell proliferation assays. Cell proliferation was measured by 3-(4,5-demethylthiazol-2-yl)-2,5-diphenyl tetrazolium bromide (MTT) assay. LM8 cells were seeded onto flat-bottomed, 96-well plates at a concentration of $5 \times 10^{3}$ cells/well and cultured in DMEM supplemented with $10 \%$ FBS at $37^{\circ} \mathrm{C}$ overnight. Cells were incubated with DMEM containing HA of different molecular weights including 270, 800, and $2300 \mathrm{kDa}$ at various concentrations $(0-25 \mu \mathrm{g} / \mathrm{ml})$. The cell proliferation on exogenous HA was then measured daily over 3 days. Further, for inhibition of endogenous HA synthesis, cells were pretreated with MU for 24, 48, and $72 \mathrm{~h}$ before the assay. MU was dissolved in small volumes of dimethyl sulfoxide (DMSO) and added to culture medium. The final concentration of DMSO in medium did not exceed $0.1 \%$. Pretreated cells were used in the MTT assay in the presence of different concentrations of MU (0-1.2 mM).

Cell invasion assays. Cell invasion was evaluated in a Chemotaxicell chamber (Kurabo Inc., Osaka, Japan) with a polycarbonate membrane containing $8-\mu \mathrm{m}$ pores. The upper sides of the membranes were coated with $2.5 \mu \mathrm{g}$ of Matrigel (BD Biosciences, Belford, MA), reconstituted basement-membrane gel. The chamber was placed in each well of a 24-well plate filled with $1 \mathrm{ml}$ serum-free medium or DMEM containing $\mathrm{HA}$ at concentrations of $10 \mathrm{ng} / \mathrm{ml}, 100 \mathrm{ng} / \mathrm{ml}, 1 \mu \mathrm{g} / \mathrm{ml}$, or $10 \mu \mathrm{g} / \mathrm{ml}$ on HA of each molecular weight $(270,800$, and $2300 \mathrm{kDa})$. LM8 cells $\left(5 \times 10^{5}\right.$ cells) were plated in the chamber in $300 \mu \mathrm{l}$ serum-free medium. After 48 -h incubation at $37^{\circ} \mathrm{C}$, cells that had invaded the Matrigel membrane were fixed with cold methanol and stained with Gill's hematoxylin. The number of invading cells was counted in 5 randomly chosen fields per well and the mean $\pm \mathrm{SD}$ was calculated. For inhibition of endogenous HA synthesis, cell invasion assay was performed with each well of a 24-well plate filled with DMEM containing MU at different concentrations (0-0.8 mM). After 48-h incubation, the number of invading cells was counted in 10 randomly chosen fields per well.

Gelatin-degrading MMP assays by zymography. The activities of MMP2 and MMP9 in the conditioned media were assayed by gelatin zymography with The Life Gelatin Zymo Electrophoresis Kit (Life Laboratory Company, Yamagata, Japan). A total of $1 \times 10^{6}$ cells were seeded in a $35-\mathrm{mm}$ plastic dish. After 12-h incubation, LM8 cells were incubated with serumfree medium for $6 \mathrm{~h}$. After starvation, cells were stimulated with HA $(270,800$, and $2300 \mathrm{kDa})$ for $12 \mathrm{~h}$. Conditioned media, which were collected and centrifuged to remove cellular debris, were subjected to electrophoresis with Gelatin Zymo Gel Plates. After electrophoresis, gels were washed with wash buffer solution and incubated for $24 \mathrm{~h}$ at $37^{\circ} \mathrm{C}$ in enzyme reaction buffer. Then gels were stained with protein staining solution and destained with destaining solution. 
Table I. Primer sequences used in RT-PCT.

\begin{tabular}{lllc}
\hline \multicolumn{2}{c}{ Forward primer } & \multicolumn{1}{c}{ Reverse primer } & Size (bp) \\
\hline c-myc & 5'-CTCCACTCACCAGCACAACT-3' & 5'-CGTCGTTTTCCTCAATAAGTCC-3' & 390 \\
c-jun & 5'-AACTCGGACCTTCTCACGTCG-3' & 5'-TGCTGAGGTTGGCGTAGACC-3' & 355 \\
c-fos & 5'-TCCCAGAGGAGATGTCTGTG-3' & 5'-GGCTCCAGCTCTGTGACCAT-3' & 330 \\
Mouse-CD44 & 5'-GTACATCAGTCACAGACCTAC-3' & 5'-CACCATTTCCTTGAGACTTGCT-3' & 599 \\
Mouse-HAS1 & 5'-GGTCAGCTTCTTGAGCAGTCTT-3' & 5'-CTGTTGGCTCAACCAACGAA-3' & 301 \\
Mouse-HAS2 & 5'-GAATTACCCAGTCCTGGCTT-3' & 5'-GGATAAACTGGTAGCCAACA-3' & 582 \\
Mouse-HAS3 & 5'-CCTACTTTGGCTGTGTGCAA-3' & 5'-AGGCTGGACATATAGAGAAG-3' & 526 \\
Human-CD44 & 5'-GGGTCCCATACCACTCATGGATCT-3' & 5'-GGGAAAGGTTGGCGATCAGGAATA-3 & 720 \\
Human-HAS1 & 5'-GTGAGTGGCTGTACAACGCG-3' & 5'-AGAGGGACGTAGTTAGCGGC-3' & 354 \\
Human-HAS2 & 5'-GAAAGGGCCTGTCAGTCTTATTT-3' & 5'-TTCGTGAGATGCCTGTCATCACC-3' & 158 \\
Human-HAS3 & 5'-GAGCGGGCCTGCCAGTCCTACTT-3' & 5'-AGCCAAGGCTCAGGACTCGGTT-3' & 178 \\
G3PDH & 5'-ACCACAGTCCATGCCATCAC-3' & 5'-TCCACCACCCTGTTGCTGTA-3' & 450 \\
\hline
\end{tabular}

Adhesion assays. To investigate the adhesion of LM8 cells to HA of various molecular sizes, a flat-bottomed 96-well plate was coated overnight at $4^{\circ} \mathrm{C}$ with $2 \mathrm{mg} / \mathrm{ml}$ various molecular size of HA. The plate was washed twice with phosphatebuffered saline (PBS), non-specific sites were blocked with $10 \mathrm{mg} / \mathrm{ml}$ bovine serum albumin (BSA) for $1 \mathrm{~h}$ at $37^{\circ} \mathrm{C}$, and then $1 \times 10^{5}$ cells were added and allowed to adhere for $90 \mathrm{~min}$ at $4^{\circ} \mathrm{C}$. Non-adherent cells were aspirated and the number of viable cells was determined using a colorimetric assay. Briefly, adherent cells were placed in DMEM containing $0.5 \mathrm{mg} / \mathrm{ml}$ MTT (Nacalai Tesque) for $2 \mathrm{~h}$ at $37^{\circ} \mathrm{C}$, the medium was then removed, and formazan crystals were solubilized with $100 \mu \mathrm{l}$ DMSO. The optical density was measured using a microplate reader (Bio-Rad, Tokyo, Japan) at $630 \mathrm{~nm}$. To examine CD44-dependency of adhesion, LM8 cells were preincubated with anti-CD44 mAbs (KM81) at a concentration of $5 \mu \mathrm{g} /$ $1 \times 10^{6}$ cells in $1 \mathrm{ml}$ PBS for $30 \mathrm{~min}$ at $4^{\circ} \mathrm{C}$. The cells were washed 3 times with PBS and applied to adhesion assays for HA.

Hyaluronan-induced overexpression of c-fos, c-jun, and c-myc. In an effort to determine the molecular mechanisms responsible for hyaluronan-induced overexpression of protooncogenes, levels of c-fos, c-jun and c-myc mRNA were examined in LM8 cells by RT-PCR. LM8 cells were incubated with serum-free medium for $24 \mathrm{~h}$. Subsequently, the cells were stimulated with HA $(270,800$, and $2300 \mathrm{kDa})$ at a concentration of $25 \mu \mathrm{g} / \mathrm{ml}$ for the indicated amounts of time. Total RNA was extracted from the cells with the High Pure RNA Isolation Kit (Roche Applied Science, Penzberg, Germany). Expression of the protooncogenes c-fos, c-jun, and c-myc in LM8 cells were determined by RT-PCR. Sequences of the PCR primers are listed in Table I. Levels of G3PDH mRNA were monitored as internal controls.

Immunoprecipitation and Western blotting. LM8 cells were starved with serum-free medium for $24 \mathrm{~h}$ and stimulated with $\mathrm{HA}$ of different molecular sizes at a concentration of $25 \mu \mathrm{g} / \mathrm{ml}$ for the indicated times. After stimulation, cells were lysed by suspension in an ice-cold lysis buffer $(25 \mathrm{mM}$ Tris- $\mathrm{HCl}$ : pH 7.0, $100 \mathrm{mM} \mathrm{NaCl}, 0.5 \%$ Nonidet P-40, $100 \mu \mathrm{M}$ sodium orthovanadate, $10 \mu \mathrm{g} / \mathrm{ml}$ aprotinin, $10 \mu \mathrm{g} / \mathrm{ml}$ leupeptin, $1 \mu \mathrm{g} / \mathrm{ml}$ pepstatin, and $1 \mathrm{mM}$ phenylmethylsulfonyl fluoride) for $20 \mathrm{~min}$ and insoluble material was removed by centrifugation. The lysates containing approximately $200 \mu \mathrm{g}$ of total cellular protein were immunoprecipitated by incubation with the anti-FAK antibody for $3 \mathrm{~h}$ on ice. Immune complexes were collected on protein A-Agarose (Roche Applied Science) overnight, washed 3 times in PBS, and proteins were eluted with $2 \mathrm{X}$ SDS sample buffer (125 mM Tris-HCl: $\mathrm{pH} 6.8,4 \%$ SDS, $20 \%$ glycerol, $10 \%$ 2-mercaptoethanol, and $0.01 \%$ bromophenol blue) for SDS-polyacrylamide gel electrophoresis (PAGE). The proteins were resolved on SDS-PAGE and transferred to polyvinylidene difuoride membranes (Bio-Rad Laboratories, Hercules, CA, USA). Primary antibodies (antiphosphotyrosine antibody, anti-FAK antibody) reacted to the antigens on membranes were detected using HRP-linked secondary antibodies (Cell Signaling Technology, USA) and ECL detection reagents (Amersham Pharmacia Biotech, UK). Further, to investigate HA-dependent activation of MAP kinase in LM8, lysates were immunoblotted with antiphospho Erk or anti-Erk2 antibody.

\section{Results}

Expression of HAS and CD44 mRNA in LM8 cells and conventional osteosarcoma samples. To investigate expression of HAS1, HAS2, HAS3, and CD44, we confirmed the expression of mRNA in LM8 cells and 14 conventional osteosarcoma samples using RT-PCR. Transcripts of HAS3 and CD44 were detectable with amplified products of predicted size, while transcription of HAS1 and HAS2 did not occur in LM8 cells (Fig. 6A). Two samples for HAS2 and one for HAS3 exhibited weak mRNA expression; however, PCR products for HAS2 and HAS3 were detected in all 14 osteosarcoma samples. The ratio of expression of HAS1 mRNA was lower than those of 
Effect of HA on proliferation of LMB cells

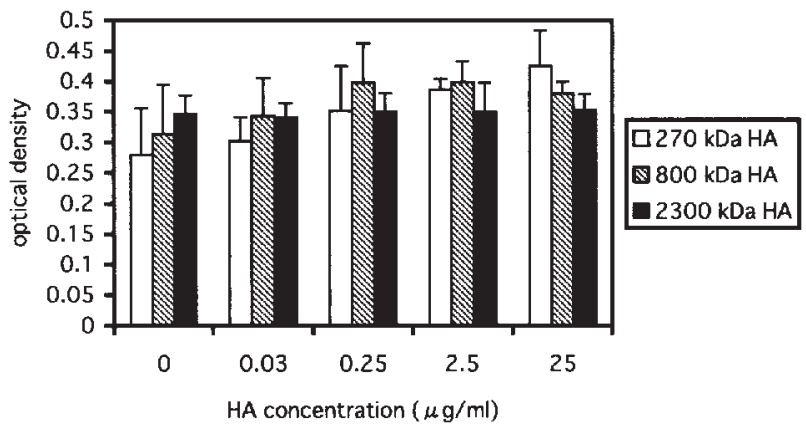

Figure 1. Effects of exogenous HA on proliferation of LM8 cells. The effects of exogenous HA of different molecular weights including 270, 800, and $2300 \mathrm{kDa}$ on proliferation of LM8 cells were evaluated using MTT assay. Cells were incubated with DMEM containing 270, 800, and $2300 \mathrm{kDa} H A$ at different concentrations $(0-25 \mu \mathrm{g} / \mathrm{ml})$. Results show the proliferation of LM8 cells after incubation with HA for $72 \mathrm{~h}$, and are the mean value $\pm \mathrm{SD}$ of triplicate experiments.

HAS2 and HAS3 mRNA in 14 conventional osteosarcoma samples (Fig. 6B).

Effects of exogenous HA on proliferation and invasion of LM8 cells. The effects of exogenous HA of different molecular sizes including 270,800 , and $2300 \mathrm{kDa}$ on proliferation of LM8 cells were evaluated by MTT assay. The effects of exogenous HA on invasion of LM8 cells were examined by

A

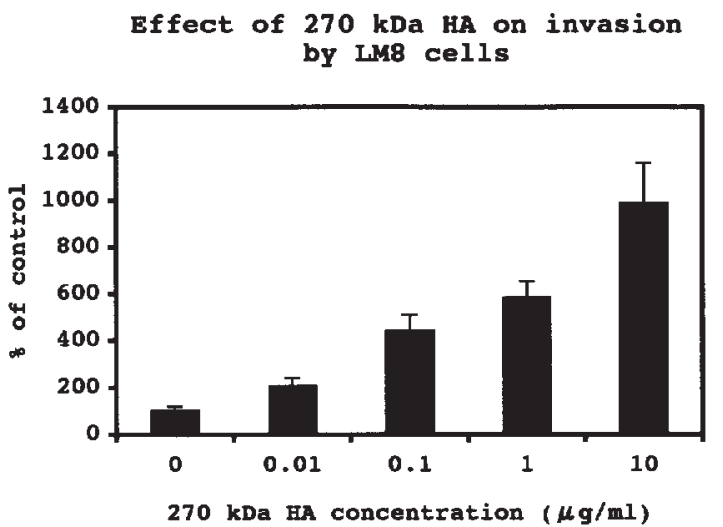

B

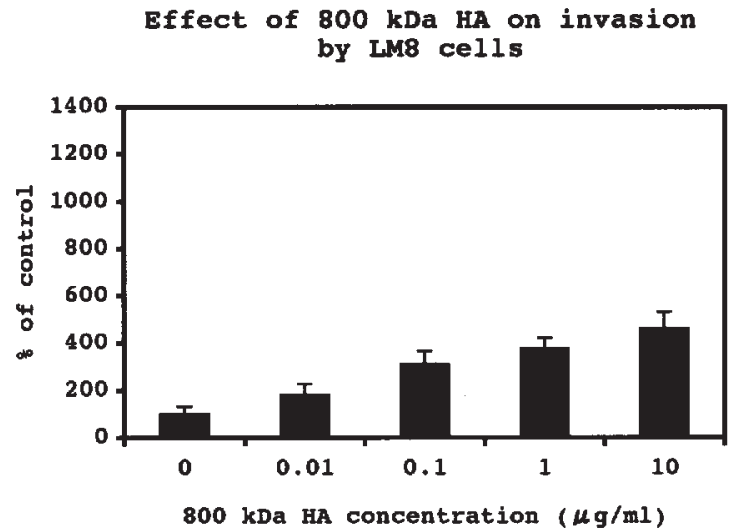

Matrigel assay. HA of 270 and $800 \mathrm{kDa}$ promoted both cell proliferation and invasion in a dose-dependent manner, and $270 \mathrm{kDa} H A$ had the strongest effects on both cell proliferation and invasion, whereas $2300 \mathrm{kDa} \mathrm{HA}$ had no effect on either cell proliferation or invasion (Figs. 1 and 2).

Effects of MU on proliferation and invasion of LM8 cells. LM8 cells were incubated with indicated doses of MU, as a suppressor of HAS3 activity, for 24, 48, and $72 \mathrm{~h}$ to inhibit endogenous HA synthesis and then proliferation was evaluated using MTT assay. Cell proliferation was inhibited by MU in a dose-dependent manner. Inhibition was apparent for cells treated with $0.4 \mathrm{mM} \mathrm{MU}$, and maximal inhibition was observed when the LM8 cells were preincubated with $1.2 \mathrm{mM} \mathrm{MU}$ (Fig. 7A). Similarly, after LM8 cells were pretreated with indicated doses of MU, the effects of MU on invasion of LM8 cells were examined by Matrigel assay. Invasion assay revealed that MU also inhibits invasion of LM8 cells. This inhibition was observed in LM8 cells pretreated with as little as $0.2 \mathrm{mM} \mathrm{MU}$, and maximal inhibition (10\%) was observed after pretreatment with $0.8 \mathrm{mM} \mathrm{MU}$ (Fig. 7B).

Effects of HA stimulation on MMP2 secretion by LM8 cells. We investigated the production of MMP2 and MMP9 resulting from HA stimulation of LM8 cells. Treatment of LM8 cells with $270 \mathrm{kDa}$ HA strongly activated MMP2 secretion in a dose-dependent manner (Fig. 3A). In contrast, gelatindegrading activity corresponding to the size of MMP9 $(92 \mathrm{kDa})$ was not detectable. In addition, we examined the effect of

C Effect of $2300 \mathrm{kDa}$ HA on invasion by LM8 cells

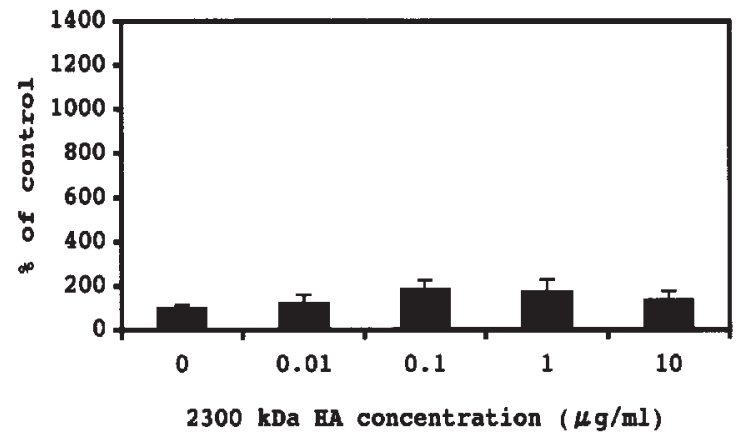

Figure 2. Effects of exogenous HA on invasion by LM8 cells. The effects of exogenous HA of different molecular weights (A) 270, (B) 800, and (C) $2300 \mathrm{kDa}$ on invasion by LM8 cells were examined by Matrigel assay. Cells were treated for $48 \mathrm{~h}$ with HA and the number of invading cells was counted in 5 randomly chosen fields per well in 2 separate wells. The invasive potential of control cells was normalized to $100 \%$ invasion and the invasive potential of cells treated with HA was calculated as a percentage of the control. Values are the mean \pm SD of triplicate experiments. 


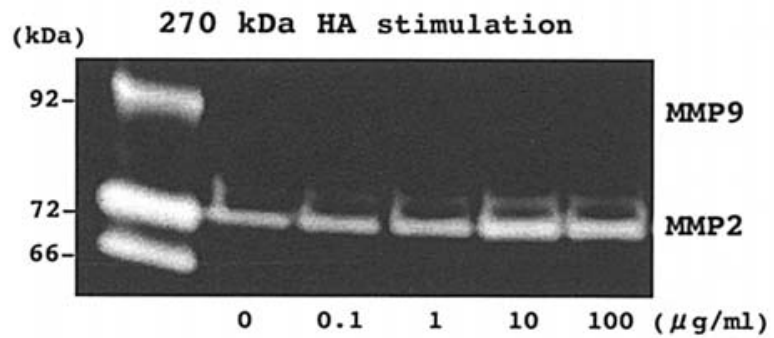

B

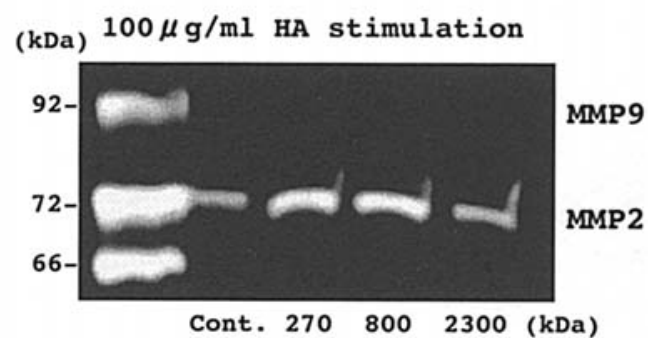

Figure 3. Effects of HA stimulation on MMP secretion by LM8 cells. LM8 cells were incubated with serum-free medium for $6 \mathrm{~h}$. After starvation, cells were stimulated (A) with $270 \mathrm{kDa}$ HA for the indicated concentrations or (B) with HA $(100 \mu \mathrm{g} / \mathrm{ml})$ of different molecular weights $(270,800$, and $2300 \mathrm{kDa}$ ) for $12 \mathrm{~h}$. Conditioned media were collected and subjected to gelatin zymography.

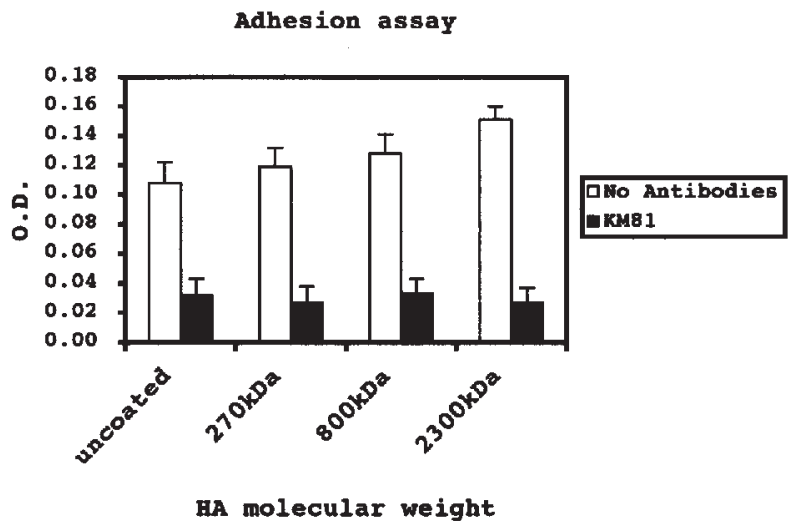

Figure 4. Adhesion of LM8 cells to HA of different molecular weights. Adhesion of cells pretreated with anti-CD44 mAbs (KM81) or non-treated cells to plates coated or uncoated with HA of different molecular weights $(270,800$, and $2300 \mathrm{kDa})$ was evaluated at $90 \mathrm{~min}$. Values are the mean $\pm \mathrm{SD}$ of triplicate experiments.

270, 800, and $2300 \mathrm{kDa}$ exogenous HA. These exogenous HAs all stimulated MMP2 secretion, though stimulation with exogenous HA with smaller molecular sizes such as 270 and $800 \mathrm{kDa}$ yielded higher activities (Fig. 3B).

Adhesion of LM8 cells to different sizes of HA. LM8 cells were tested for their ability to bind HA-coated plates. LM8 cells exhibited significantly higher adhesion to HA-coated plates than baseline adhesion to uncoated plates. Moreover, LM8 cells were most adherent to $2300 \mathrm{kDa} H \mathrm{HA}$. This adhesion to HA was CD44-dependent, because pretreatment of LM8 cells with anti-CD44 mAbs (KM81) significantly reduced binding of HA (Fig. 4). Taken together, these observations imply that LM8 cells use CD44 as an adhesion receptor for
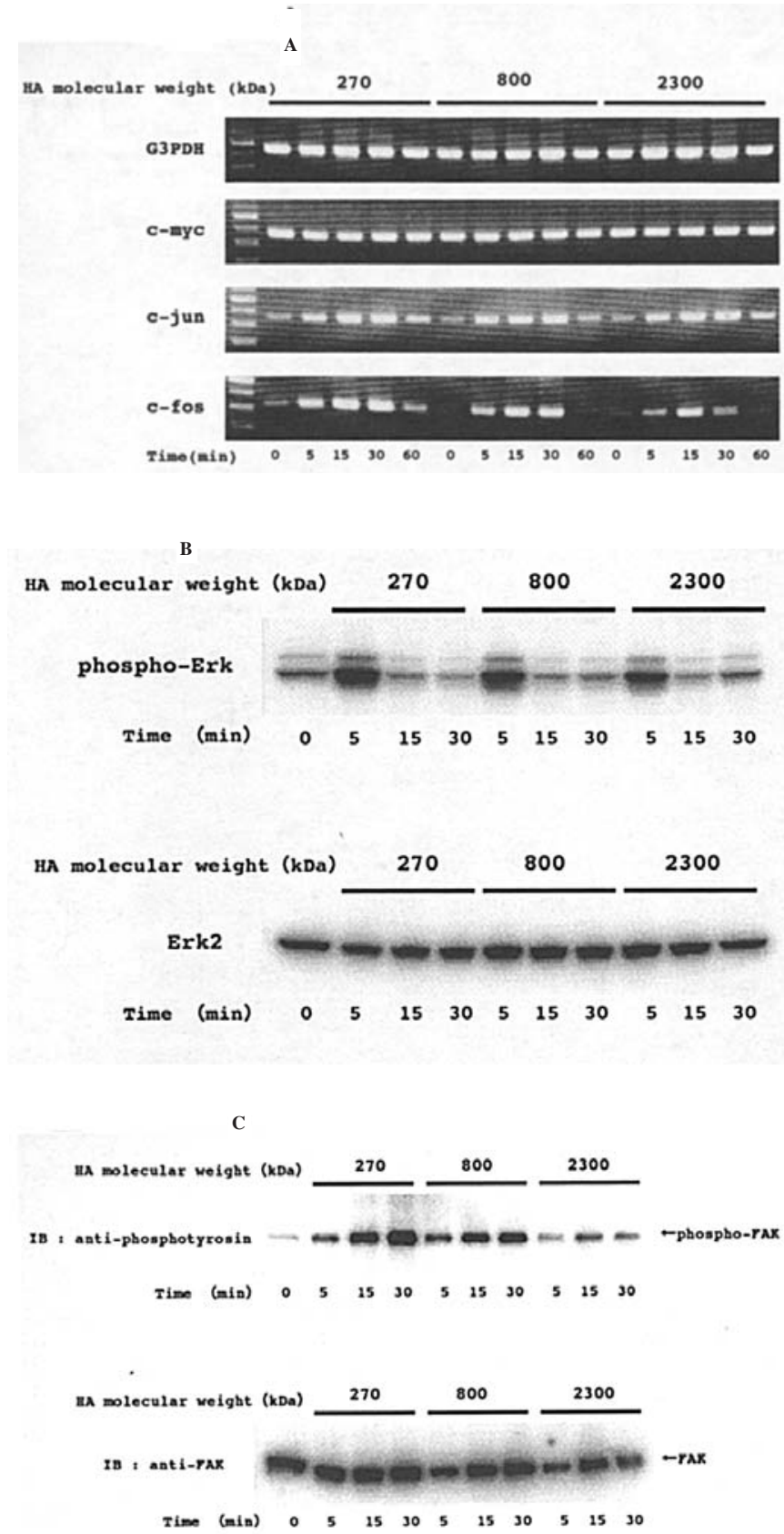

IP: anti-rax

Figure 5. Effects of HA on protooncogene expression, activation of MAP kinase and tyrosine phosphorylation of FAK in LM8 cells. (A) Time course of induction of immediate-early genes by HA $(270,800$, and $2300 \mathrm{kDa})$ in LM8 cells. Total RNA was extracted from cultured LM8 cells at different times after adding $25 \mu \mathrm{g} / \mathrm{ml}$ of HA to the culture medium and reverse-transcribed. The resulting cDNA was amplified with specific primers for c-fos, c-jun, and c-myc. Levels of G3PDH mRNA were monitored as internal controls. (B) LM8 cells were starved with serum-free medium for $24 \mathrm{~h}$ and stimulated with HA of different molecular weights $(270,800$, and $2300 \mathrm{kDa})$ at a concentration of $25 \mu \mathrm{g} / \mathrm{ml}$ for the indicated times. Cell lysates were subjected to immunoblot analysis using anti-phospho Erk antibody (upper panel) or anti-Erk2 antibody (lower panel). (C) LM8 cells were stimulated with HA of different molecular weights $(270,800$, and $2300 \mathrm{kDa})$ for various periods. Lysates were immunoprecipitated with anti-FAK antibody and blotted sequentially with anti-phosphotyrosine antibody (upper panel) and anti-FAK antibody (lower panel).

pericellular HA matrices and that high-molecular-weight HAs such as $2300 \mathrm{kDa} H A$ play a key role in pericellular HA matrix formation. 
A

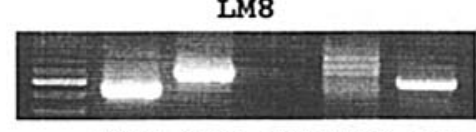

G3PDH CD44 HAS1 HAS2 HAS 3

B

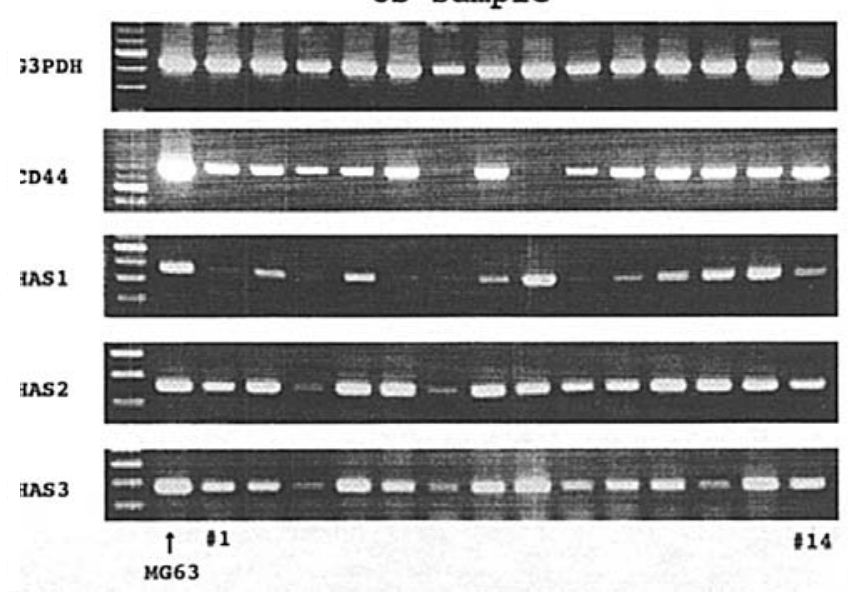

Figure 6. Expression of CD44, HAS1, HAS2, and HAS3 mRNA in LM8 cells and conventional osteosarcoma samples. Total RNA was reverse-transcribed and the resulting cDNA was amplified with specific primers for G3PDH, CD44, HAS1, HAS2, and HAS3. Levels of G3PDH mRNA were monitored as internal controls. (A) Expression of CD44, HAS1, HAS2, and HAS3 mRNA in LM8 cells. (B) Expression of CD44, HAS1, HAS2, and HAS3 mRNA in 14 conventional osteosarcoma samples. MG63 cells served as a positive control for CD44, HAS1, HAS2 and HAS3.

Effects of HA on c-fos, c-jun, and c-myc expression in LM8 cells. We examined the inducibility of transcription factors by HA in LM8 cells. Cells rendered quiescent by serum starvation for $24 \mathrm{~h}$ were driven to re-enter the cell cycle by HA stimulation. At different times after addition of 270, 800, and $2300 \mathrm{kDa} \mathrm{HA}$, total RNA was extracted and analyzed by RT-PCR. Expression of c-myc was already very strong without HA stimulation and remained unmodified by HA. Expression of c-jun peaked at 30 min with any molecular size of HA, and no difference in extent of expression was detectable among different sizes of HA. Expression of c-fos peaked between $15 \mathrm{~min}$ and $30 \mathrm{~min}$ and rapidly returned to basal levels. Moreover, the up-regulation of c-fos induced by $270 \mathrm{kDa} H A$ was obviously higher than that induced by 2300 kDa HA (Fig. 5A).

Effect of HA on activation of MAP kinase in LM8 cells. To determine whether the MAP kinases Erk1 and Erk2 are activated by HA stimulation in LM8 cells and whether there is a difference in degree of MAP kinase activation among HAs of different molecular weights, we investigated the HA-dependent activation of MAP kinase in cells stimulated by HA of different molecular weights including 270, 800, and $2300 \mathrm{kDa}$. Cells were stimulated with HA for the indicated times and subsequently probed with anti-phospho Erk or anti-Erk2 antibodies. In cells stimulated with HA of any molecular weight, phosphorylation of MAP kinase was transient, occurring at $5 \mathrm{~min}$ in response to HA and ceasing by $15 \mathrm{~min}$. In addition, $270 \mathrm{kDa} H A$ had the greatest effects on phosphorylation of MAP kinase (Fig. 5B).
$\mathbf{A}$

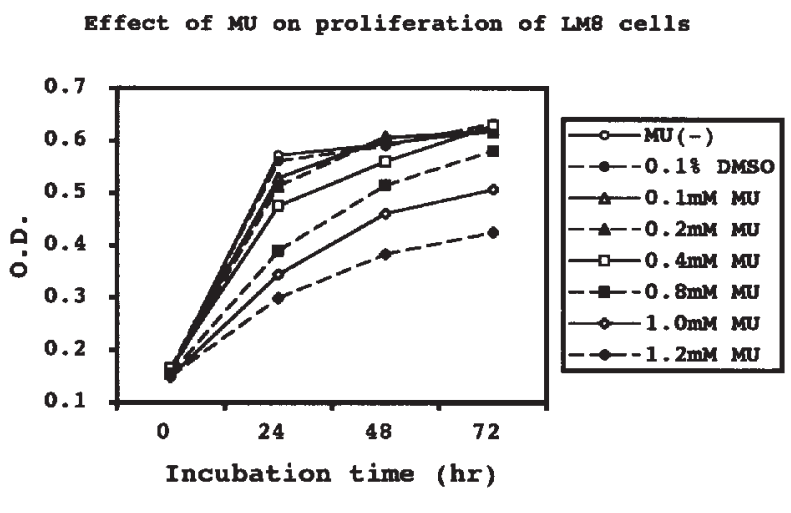

B

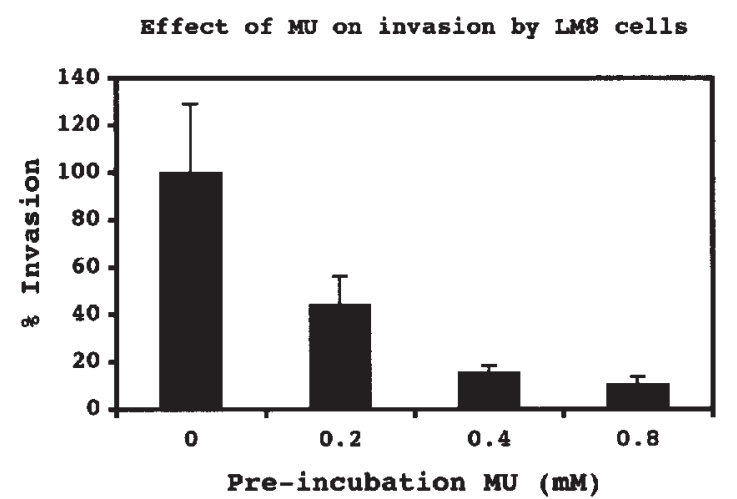

Figure 7. Effects of MU on proliferation and invasion of LM8 cells. (A) LM8 cells were incubated with 0-1.2 mM MU for various periods of times. Proliferation was determined using MTT assay. Values are the mean \pm SD of triplicate experiments. (B) LM8 cells that had been preincubated with various concentrations of MU were subjected to cell invasion assay. Cells were treated for $48 \mathrm{~h}$ with MU and the number of invading cells was counted in 10 randomly chosen fields per well in 2 separate wells. The invasive potential of control cells was normalized to $100 \%$ invasion and the invasive potential of cells treated with MU was calculated as a percentage of the control. Values are the mean \pm SD of triplicate experiments.

Effect of HA on tyrosine phosphorylation of FAK in LM8 cells. To confirm and extend our observation, we examined the effect of HA stimulation on tyrosine phosphorylation of FAK. FAK is a tyrosine kinase located in focal contact that regulates not only cell motility but also anti-apoptotic intracellular signaling against certain pro-apoptotic stimuli. HA of 270 and $800 \mathrm{kDa}$ molecular weight activated tyrosine phosphorylation of FAK in a time-dependent manner, whereas tyrosine phosphorylation of FAK was activated by $2300 \mathrm{kDa}$ HA, with a peak at $15 \mathrm{~min}$ and a decrease after $15 \mathrm{~min}$ of treatment. The most notable finding was that $270 \mathrm{kDa} H A$ had the greatest effects on tyrosine phosphorylation of FAK (Fig. 5C).

\section{Discussion}

Despite advances in multidisciplinary treatment, including chemotherapy, some osteosarcoma patients still develop pulmonary metastasis and have a poor prognosis. The molecular mechanism of metastasis in osteosarcoma, as in other malignant tumors, is still unclear. 
It has been reported that HA plays an important role in the acquisition of malignancy in many tumors. However, the exact molecular mechanisms by which HA affects invasion and metastasis remain unclear. Although it has been found that the biological activity of HA in invasion and metastasis varies depending on molecular weight, this has not been investigated for osteosarcoma. In this study, we examined the molecular weight of HA associated with metastasis, and also the related HAS.

Proliferation was promoted when stimulated by HA with molecular weight of either 270 or $800 \mathrm{kDa}$. On the other hand, HA of $2300 \mathrm{kDa}$ had no effect on cell proliferation. The importance of the classical MAPK cascade in the signal transduction pathway for cell growth has been widely accepted. In the cascade, phosphorylation on ERK was found to be more predominant when stimulated with $270 \mathrm{kDa} H A$, than with HA of higher molecular weight. Stimulation with $270 \mathrm{kDa}$ HA also led to the most remarkable expression of mRNA of c-fos, a typical immediate early gene, often detected among various types of tumor cells in consequence of growth signal stimulation. Thus, signal transduction via the classical MAPK cascade was required for the cell proliferation in response to stimulation with 270 or $800 \mathrm{kDa} H A$.

Likewise, invasion was promoted by HA with molecular weight of either 270 or $800 \mathrm{kDa}$. The $270 \mathrm{kDa}$ HA resulted in the highest activity. FAK is a subset of integrin signaling molecules, known to function in integrin signaling via tyrosine phosphorylation. It is thought to be involved in the turnover of focal adhesion contacts during cell migration (27), and is required to sustain collective cell migration (28). Furthermore, FAK plays a role in adhesion-dependent cell survival (29) and mediation of anti-apoptotic effects (30). In our study, FAK was phosphorylated the most when stimulated by $270 \mathrm{kDa}$ HA. It can thus be assumed that promotion of motility would result in a high rate of invasion.

In addition to proliferation and motility, the degradation of extracellular matrix is a critical biological activity for invasion and metastasis of tumors. Production of MMP may be an important factor in causing extracellular matrix degradation. Studies have shown that production of MMP was facilitated by various cytokines such as IL-1ß and $\mathrm{TGF} \alpha(31,32)$. It was also found that HA stimulation against QG90, a human lung carcinoma cell line, could trigger MMP2 secretion in a FAK-dependent manner (33). In our study, more intense production of MMP2 was observed with stimulation by HA of 270 or $800 \mathrm{kDa}$, which promoted further degradation of extracellular matrix than $2300 \mathrm{kDa}$ HA.

It can be concluded that HA with molecular weights of 270 and $800 \mathrm{kDa}$ significantly contributes to proliferation, invasion, and extracellular matrix degeneration. In particular, $270 \mathrm{kDa} H A$ has a profound effect on these biological activities, which are important for metastasis and invasion.

$\mathrm{HA}$ is a high-molecular-weight linear polymer composed of repeating units of GlcNAc- $\beta(1 \rightarrow 4)$-GlcUA- $\beta(1 \rightarrow 3)$ and is synthesized by HA synthase at the inner face of the plasma membrane (34). In mammals, three type of HAS - HAS1, HAS2, and HAS3 - have been reported (21-23). However, these three isoforms have different biological properties, e.g., the rate at which they carry out hyaluronan synthesis, with HAS3 more active than both HAS1 and HAS2 in this respect. HAS2 and HAS3 produce larger HAS pericellular matrices than HAS1. HAS1 exhibits higher enzymatic activity $(\mathrm{Km})$ for both UDP-GlcNAc and UDP-GlcUA than HAS2 and HAS3. HAS3 synthesizes HA with molecular weights of $1 \times 10^{5}-1 \times 10^{6} \mathrm{Da}$, shorter than the HA synthesized by HAS1 and HAS2, which has molecular weights of $2 \times 10^{5}-2 \times 10^{6} \mathrm{Da}$. Moreover, HAS1 and HAS3 produce HA with broad size distributions, whereas HAS2 secrets extremely large HA (average molecular weight of $\left.>2 \times 10^{6} \mathrm{Da}\right)(23,35,36)$.

Of the various biological functions of HA, some appear to be size-dependent. Therefore, adjustment of HA function can be achieved by regulating the activity and expression of the three HAS isoforms. Based on the characteristic size of HA synthesized by each type of HAS, we can assess that the molecular weight of HA, which was demonstrated to be essential in promoting invasion and metastasis in our experiments, is consistent with the molecular weight of HA related to HAS3. Furthermore, of the three isoforms, HAS3 was found to be the only one expressed in LM8, a murine osteosarcoma cell line with high pulmonary metastatic potential. This suggests that HAS3 and its product may be important in promoting biological activities required for invasion and metastasis.

In this study, we used MU to suppress HAS3 activity. MU has been used as an inhibitor of HA synthesis in some studies on the functions of HA, although the precise mechanism by which it inhibits HA synthesis has not been established for mammalian cells $(37,38)$. Several mechanisms have been proposed for the inhibition of HA synthesis by MU. For example, MU was found to inhibit HA synthesis in cultured human skin fibroblasts but to have no effect on the synthesis of any other glycosaminoglycan (39). MU did not affect expression of the HAS gene but altered the lipid environment of the membrane, especially the distribution of different cardiolipin species, surrounding HAS (40). MU-mediated inhibition of HA synthesis involving the glucuronidation of MU is due, in part, to depletion of the pool of UDP-GlcUA, a common substrate of HAS and UGT. Recently, it has been reported that MU has an inhibitory effect on the biological activities required for invasion and metastasis $(41,42)$.

Suppression of proliferation and invasion were observed with inhibition of HAS3 expressed in LM8 by MU. Thus, after synthesized by HAS3 activity, HA should function as a stimulative factor in autocrine/paracrine fashion, and promote invasion and metastasis by initiating intracellular signal transduction.

Recently, HA-rich pericellular coat formation has been reported for various malignant tumor cells $(43,44)$. HA-rich pericellular coat prevents the generation of cytotoxic T lymphocytes which are specific to surface antigens on the tumor cell, and protects against cytolytic lymphocytes $(26,45)$. Also, active synthesis of HA occurs in vigorously dividing cells because it facilitates cell detachment $(25,46)$. Additionally, HA-rich environment facilitates hydration of tissue, and thus provides favorable conditions for carcinoma cells regarding growth and invasion. In this study, we examined the adhesive capacity of HA of different weights for CD44, which is expressed on LM8 cells as the HA receptor. The strongest adhesion was observed with $2300 \mathrm{kDa} \mathrm{HA}$, indicating that 
HA of large molecular weight is involved in the formation of a pericellular coat. Therefore, HAS2, which synthesizes an extremely large HA (average $>2 \times 10^{6} \mathrm{Da}$ ), may play a crucial role in the formation of the pericellular coat. A recent study reported that formation of the pericellular coat, on osteosarcoma cell line MG63, was suppressed by treatment with HAS2 antisense oligonucleotides (47). This finding does not conflict with the findings of our study.

In addition, in samples from osteosarcoma patients, HAS2 and HAS3 were transcribed more than HAS1, suggesting that both HAS2 and HAS3 participate in invasion and metastasis by producing HA of different molecular weights.

In conclusion, HA secreted by HAS3 behaves as a stimulative factor to trigger intracellular signal transduction pathways, which converge to promote biological activities necessary for invasion and metastasis. On the other hand, HA secreted by HAS2 binds to CD44, and functions in pericellular coat formation and hydration in the extracellular space, thus offering an advantageous environment for osteosarcoma cells. The activity of HAS2 and HAS3 in tumor cells can be controlled by molecular-targeted therapy to prevent pulmonary metastasis and improve the prognosis of osteosarcoma.

\section{Acknowledgements}

We thank Ms Gao Hui for excellent technical assistance. We also thank Seikagaku Corp. for the kind gift of HA.

\section{References}

1. Meyers PA and Gorlick R: Osteosarcoma. Pediatr Clin North Am 44: 973-989, 1997.

2. Bertrand P, Girard N, Delpech B, Duval C, d'Anjou J and Dauce JP: Hyaluronan (hyaluronic acid) and hyaluronectin in the extracellular matrix of human breast carcinomas: comparison between invasive and noninvasive areas. Int J Cancer 52: 1-6, 1992.

3. De la Torre M, Wells AF, Bergh J and Lindgren A: Localization of hyaluronan in normal breast tissue, radial scar, and tubular breast carcinoma. Hum Pathol 24: 1294-1297, 1993.

4. Auvinen PK, Parkkinen JJ, Johansson RT, Agren UM, Tammi RH, Eskelinen MJ and Kosma V-M: Expression of hyaluronan in benign and malignant breast lesions. Int J Cancer 74: 477-481, 1997.

5. Horai T, Nakamura N, Tateishi R and Hattori S: Glycosaminoglycans in human lung cancer. Cancer 48: 2016-2021, 1981.

6. Ropponen K, Tammi M, Parkkinen J, Eskelinen M, Tammi R, Lipponen P, Agren U, Alhave E and Kosma V-M: Tumor cellassociated hyaluronan as an unfavorable prognostic factor in colorectal cancer. Cancer Res 58: 342-347, 1998.

7. Azumi N, Underhill CB, Kagan E and Sheibani K: A novel biotinylated probe specific for hyaluronate: its diagnostic value in diffuse malignant mesothelioma. Am J Surg Pathol 16: 116-121, 1992.

8. Laurent TC and Fraser JR: Hyaluronan. FASEB J 6: 2397-2404, 1992.

9. Toole BP, Wight TN and Tammi MI: Hyaluronan-cell interactions in cancer and vascular disease. J Biol Chem 277: 4593-4596, 2002.

10. Bartolazzi A, Peach R, Aruffo A and Stamenkovic I: Interaction between CD44 and hyaluronate is directly implicated in the regulation of tumor development. J Exp Med 180: 53-66, 1994.

11. Zhang S, Chang MC, Zylka D, Turley S, Harrison R and Turley EA: The hyaluronan receptor RHAMM regulates extracellular-regulated kinase. J Biol Chem 273: 11342-11348, 1998.

12. Banerji S, Ni J, Wang SX, Clasper S, Su J, Tammi R, Jones M and Jackson DC: LYVE-1, a new homologue of the CD44 glycoprotein, is a lymph-specific receptor for hyaluronan. J Cell Biol 144: 789-801, 1999.
13. Knudson $\mathrm{CB}$ and Knudson W: Hyaluronan-binding proteins in development, tissue homeostasis, and disease. FASEB J 7: 1233-1241, 1993.

14. Gunthert U, Hofmann M, Rudy W, Reber S, Zoller M, Haussmann I, Matzku S, Wenzel A, Ponta H and Herrlich P: A new variant of glycoprotein CD44 confers metastatic potential to rat carcinoma cells. Cell 65: 13-24, 1991.

15. Heider KH, Hofmann M, Hors E, van den Berg F, Ponta H, Herrlich P and Pals ST: A human homologue of the rat metastasisassociated variant of CD44 is expressed in colorectal carcinomas and adenomatous polyps. J Cell Biol 120: 227-233, 1993.

16. Dall P, Heider KH, Sinn HP, Skroch-Angel P, Adolf G, Kaufmann M, Herrlich P and Ponta H: Comparison of immunohistochemistry and RT-PCR for detection of CD44vexpression, a new prognostic factor in human breast cancer. Int J Cancer 60: 471-477, 1995.

17. Kainz C, Tempfer C, Winkler S, Sliutz G, Koelbl H and Reinthaller A: Serum CD44 splice variants in cervical cancer patients. Cancer Lett 90: 231-234, 1995.

18. Kuryu M, Ozaki T, Nishida K, Shibahara M, Kawai A and Inoue $\mathrm{H}$ : Expression of CD44 variants in osteosarcoma. J Cancer Res Clin Oncol 125: 646-652, 1999.

19. Forrester JV and Balazs EA: Inhibition of phagocytosis by high molecular weight hyaluronate. Immunology 40: 435-446, 1980 .

20. West DC, Hampson IN, Arnold F and Kumar S: Angiogenesis induced by degradation products of hyaluronic acid. Science 228: 1324-1326, 1985.

21. Weigel PH, Hascall VC and Tammi M: Hyaluronan synthases. J Biol Chem 272: 13997-14000, 1997.

22. Kumari K and Weigel PH: Molecular cloning, expression, and characterization of the authentic hyaluronan synthase from group C Streptococcus equisimilis. J Biol Chem 272: 32539-32546, 1997.

23. Itano N, Sawai T, Yoshida M, Lenas P, Yamada Y, Imagawa M, Shinomura T, Hamaguchi M, Yoshida Y, Ohnuki Y, Miyauchi S, Spicer AP, McDonald JA and Kimata K: Three isoforms of mammalian hyaluronan synthases have distinct enzymatic properties. J Biol Chem 274: 25085-25092, 1999.

24. Asai T, Ueda T, Itoh K, Yoshioka K, Aoki Y, Mori S and Yoshikawa $\mathrm{H}$ : Establishment and characterization of a murine osteosarcoma cell line (LM8) with high metastatic potential to the lung. Int J Cancer 76: 418-422, 1998.

25. Matuoka K, Namba M and Mitsui Y: Hyaluronate synthetase inhibition by normal and transformed human fibroblasts during growth reduction. J Cell Biol 104: 1105-1115, 1987.

26. McBride WH and Bard JB: Hyaluronidase-sensitive halos around adherent cells. Their role in blocking lymphocytemediated cytolysis. J Exp Med 149: 507-515, 1979

27. Ilic D, Furuta Y, Kanazawa S, Takeda N, Sobue K, Nakatsuji N, Nomura S, Fujimoto J, Okada M and Yamamoto T: Reduced cell motility and enhanced focal adhesion contact formation in cells from FAK-deficient mice. Nature 377: 539-544, 1995.

28. Yano H, Mazaki Y, Kurokawa K, Hanks SK, Matsuda M and Sabe H: Roles played by a subset of integrin signaling molecules in cadherin-based cell-cell adhesion. J Cell Biol 166: 283-295, 2004.

29. Frisch SM, Vuori K, Ruoslahti E and Chan-Hui PY: Control of adhesion-dependent cell survival by focal adhesion kinase. J Cell Biol 134: 793-799, 1996.

30. Sonoda Y, Matsumoto Y, Funakoshi M, Yamamoto D, Hanks SK and Kasahara T: Anti-apoptotic role of focal adhesion kinase (FAK). Induction of inhibitor-of-apoptosis proteins and apoptosis suppression by the overexpression of FAK in a human leukemic cell line, HL-60. J Biol Chem 275: 16309-16315, 2000.

31. Lyons JG, Birkedal-Hansen B, Pierson MC, Whitelock JM and Birkedal-Hansen H: Interleukin-1 beta and transforming growth factor-alpha/epidermal growth factor induce expression of $\mathrm{M}(\mathrm{r})$ 95,000 type IV collagenase/gelatinase and interstitial fibroblasttype collagenase by rat mucosal keratinocytes. J Biol Chem 268: 19143-19151, 1993.

32. Librach CL, Feigenbaum SL, Bass KE, Cui TY, Verastas N, Sadovsky Y, Quigley JP, French DL and Fisher SJ: Interleukin-1 beta regulates human cytotrophoblast metalloproteinase activity and invasion in vitro. J Biol Chem 269: 17125-17131, 1994.

33. Zhang Y, Thant AA, Hiraiwa Y, Naito Y, Sein TT, Sohara Y, Matsuda S and Hamaguchi M: A role for focal adhesion kinase in hyluronan-dependent MMP-2 secretion in a human small-cell lung carcinoma cell line, QG90. Biochem Biophys Res Commun 290: 1123-1127, 2002. 
34. Philipson LH and Schwartz NB: Subcellular localization of hyaluronate synthetase in oligodendroglioma cells. J Biol Chem 259: 5017-5023, 1984

35. Spicer AP and McDonald JA: Characterization and molecular evolution of a vertebrate hyaluronan synthase gene family. $\mathrm{J}$ Biol Chem 273: 1923-1932, 1998.

36. Spicer AP and Nguyen TK: Mammalian hyaluronan synthases: investigation of functional relationships in vivo. Biochem Soc Trans 27: 109-115, 1999.

37. Kosaki R, Watanabe K and Yamaguchi Y: Overproduction of hyaluronan by expression of the hyaluronan synthase Has2 enhances anchorage-independent growth and tumorigenicity. Cancer Res 59: 1141-1145, 1999.

38. Sohara Y, Ishiguro N, Machida K, Kurata H, Thant AA, Senga T, Matsuda S, Kimata K, Iwata $\mathrm{H}$ and Hamaguchi M: Hyaluronan activates cell motility of v-Src-transformed cells via Ras-mitogenactivated protein kinase and phosphoinositide 3-kinase-Akt in a tumor-specific manner. Mol Biol Cell 12: 1859-1868, 2001.

39. Nakamura T, Takagaki K, Shibata S, Tanaka K, Higuchi T and Endo M: Hyaluronic-acid-deficient extracellular matrix induced by addition of 4-methylumbelliferone to the medium of cultured human skin fibroblasts. Biochem Biophys Res Commun 208: 470-475, 1995.

40. Kakizaki I, Takagaki K, Endo Y, Kudo D, Ikeya H, Miyoshi T, Baggenstoss BA, Tlapak-Simmons VL, Kumari K, Nakane A, Weigel PH and Endo M: Inhibition of hyaluronan synthesis in Streptococcus equi FM100 by 4-methylumbelliferone. Eur J Biochem 269: 5066-5075, 2002.
41. Kudo D, Kon A, Yoshihara S, Kakizaki I, Sasaki M, Endo M and Takagaki K: Effect of a hyaluronan synthase suppressor, 4-methylumbelliferone, on B16F-10 melanoma cell adhesion and locomotion. Biochem Biophys Res Commun 321: 783-787, 2004.

42. Yoshihara S, Kon A, Kudo D, Nakazawa H, Kakizaki I, Sasaki M, Endo $\mathrm{M}$ and Takagaki K: A hyaluronan synthase suppressor, 4-methylumbelliferone, inhibits liver metastasis of melanoma cells. FEBS Lett 579: 2722-2726, 2005.

43. Itano N, Sawai T, Miyaishi O and Kimata K: Relationship between hyaluronan production and metastatic potential of mouse mammary carcinoma cells. Cancer Res 59: 2499-2504, 1999.

44. Bullard KM, Kim HR, Wheeler MA, Wilson CM, Neudauer CL, Simpson MA and McCarthy JB: Hyaluronan synthase-3 is upregulated in metastatic colon carcinoma cells and manipulation of expression alters matrix retention and cellular growth. Int $\mathbf{J}$ Cancer 107: 739-746, 2003.

45. Dick SJ, Macchi B, Papazoglou S, Oldfield EH, Kornblith PL, Smith BH and Gately MK: Lymphoid cell-glioma cell interaction enhances cell coat production by human gliomas: novel suppressor mechanism. Science 220: 739-742, 1983.

46. Brecht M, Mayer U, Schlosser E and Prehm P: Increased hyaluronate synthesis is required for fibroblast detachment and mitosis. Biochem J 239: 445-450, 1986.

47. Nishida Y, Knudson W, Knudson CB and Ishiguro N: Antisense inhibition of hyaluronan synthase-2 in human osteosarcoma cells inhibits hyaluronan retention and tumorigenicity. Exp Cell Res 307: 194-203, 2005. 